\title{
CONTRIBUIÇÕES DA EDUCAÇÃO PERMANENTE EM SERVIÇO NO CONTEXTO DA ESTRATÉGIA DE SAÚDE DA FAMÍLIA
}

\author{
Valquiria Coelho Pina Paulino ${ }^{1}$ \\ Paula Regina de Souza ${ }^{2}$ \\ Cristiane José Borges ${ }^{3}$
}

Resumo A educação permanente no Brasil tem sido adotada como política de desenvolvimento humano para o Sistema Único de Saúde (SUS). Tendo em vista este pressuposto, realizamos uma pesquisa descritivo-exploratória com abordagem qualitativa, que teve como objetivos identificar as contribuições da Educação Permanente em Saúde para os enfermeiros que atuam na Estratégia de Saúde da Família (ESF). Os enfermeiros referem que a educação permanente trás contribuições para a consolidação da ESF, estimula o aperfeiçoamento, a atualização e a qualificação dos trabalhadores para trabalhar com a comunidade. Contribui também para a conscientização das necessidades reais de saúde dos usuários, favorece o crescimento pessoal e profissional, melhora o trabalho em equipe e possibilita mudanças na prática e a melhora na qualidade da assistência.

Palavras chaves: Estratégia de Saúde da Família; Educação permanente em serviço; Enfermagem

\section{CONTRIBUTIONS TO STANDING EDUCATION SERVICE IN THE $\begin{array}{llllll}\text { CONTEXT OF THE FAMILY HEALTH } & \text { STRATEGY }\end{array}$}

Abstract: The standing education in Brazil has been adopted as politics for human development for the Unified Health System. Looking about this, we develop a descriptive exploratory research with a qualitative approach, which aims identify the contributions of standing healthcare education for nurses who works in Family Health Strategy. The nurses reported that standing education give them contributions to the consolidation of FHS, encourages improvement, upgrading and qualification of the professionals to work with the community. Also contributes to the knowledge of the real needs of health for users, promotes personal and professional growth, improve teamwork, and propose changes in practice and improved quality of care. 
Keywords: Family Health Strategy; Standing education in Service; Nursery.

\section{INTRODUÇÃO}

A educação permanente em serviço tem sido adotada no Brasil como política de desenvolvimento humano para o Sistema Único de Saúde (SUS). Apresenta-se como uma proposta de ação estratégica em cumprimento à Constituição de 1988, à Lei ${ }^{\circ}$ 8.080/90 e à Norma Operacional Básica de Recursos Humanos do Sistema Único de Saúde (NOB/RH-SUS). Aprovada enquanto política pelas Portarias 198/2004, 1.996/2007, 43/2007 e 48/2007(BRASIL, 2005; BRASIL, 2007), durante alguns anos a Educação Permanente se referia à educação fora da escola. Recentemente, a UNESCO inseriu esse conceito em vários países como um modelo diferenciado de educação para adultos, proposta para reorientar a educação dos trabalhadores da saúde (BRASIL, 2005).

No Brasil, tem sido adotada como política de qualificação dos profissionais de saúde e, nessa proposta, utiliza como tendência a pedagogia da problematização, sustentada na concepção de aprendizagem significativa que produza sentido e proporcione a transformação das atividades profissionais mediante a reflexão crítica sobre as práticas reais dos serviços de saúde (BRASIL, 2007; GADOTTI, 2000).

É considerada como estratégia fundamental para a reformulação das práticas de gestão, de atenção, formação e controle social, uma vez que o processo de aprendizagem tem natureza participativa e apresenta como eixo principal o cotidiano nos serviços de saúde (CECCIM; FEUERWEKER, 2004).

$\mathrm{Na}$ Estratégia de Saúde da Família (ESF), a educação permanente em serviço constitui-se como um instrumento essencial na capacitação e qualificação dos profissionais, buscando as lacunas de conhecimentos e atitudes, dando subsídios para que eles possam entender e atender às necessidades de saúde da população, de resolutividade, de organização dos serviços e de transformação da realidade (BRASIL, 2005).

O trabalho que ora se apresenta teve como pressupostos: a ESF como estratégia prioritária da Atenção Básica; sua expansão em todo país; a importância das capacitações para formação e qualificação dos profissionais que atuam nesta estratégia; 
os investimentos recentes feitos neste processo; o enfermeiro enquanto ator essencial na ESF e no processo de educação permanente em serviço.

A partir destes pressupostos, elaborou-se esta pesquisa que teve como cenário a Estratégia de Saúde da Família em um dos Distritos Sanitários de Goiânia e como sujeitos os enfermeiros que atuam na ESF, objetivando caracterizar os enfermeiros que atuam na ESF, identificar os fatores que dificultam e facilitam o processo de educação permanente na ESF e verificar as contribuições da educação permanente em serviço para os profissionais que atuam na ESF.

Este artigo é uma parte da dissertação de mestrado e nele discutimos as contribuições do processo de educação permanente sob a ótica dos enfermeiros que atuam na Estratégia de Saúde da Família e participaram de capacitações oferecidas pela Secretaria Municipal e Estadual de Saúde.

\section{METODOLOGIA}

Trata-se de uma pesquisa descritivo-exploratória com abordagem qualitativa. A pesquisa foi realizada em um dos Distritos Sanitários do município de Goiânia-GO.

Os sujeitos da pesquisa foram 12 enfermeiros que atuam na ESF. Para a coleta de dados foi criado um instrumento, composto por perguntas fechadas, que abordaram aspectos socioeconômicos, e abertas, enfocando o entendimento dos enfermeiros sobre educação permanente, as vivências de educação permanente na ESF, as dificuldades e facilidades nesta vivência, e contribuições da educação permanente para o cotidiano de trabalho. Para análise utilizou-se Bardin ( 1977).

Atendendo ao estabelecido na Resolução no 196/96 do Conselho Nacional de Saúde, o projeto de pesquisa foi aprovado pelo Comitê de Ética do Hospital das Clínicas da Universidade Federal de Goiás, sob o protocolo n ${ }^{\circ}$ 160/06.

\section{REFERENCIAL TEÓRICO}

\section{A Estratégia de Saúde da Família}

A Estratégia de Saúde da Família tem suas origens no Programa Saúde da Família (PSF), oficializado em 1994. Constitui-se, portanto, em uma estratégia de 
estruturação de um modelo assistencial, no Brasil, com propostas de alavancar o Sistema Único de Saúde (SUS).

A atenção está focada na saúde, tendo como sujeitos do processo de ação o indivíduo, a família e a comunidade em seu espaço vital, a partir das ações da equipe de saúde (MANCIA; CABRAL; KOERICH, 2004).

O Programa Saúde da Família foi implantado, inicialmente, nas regiões norte e nordeste do país, com intervenções localizadas, tendo como foco o controle das epidemias, redução da mortalidade materno-infantil e melhoria da qualidade de vida da população. Em virtude da melhoria significativa da saúde da população, o Programa foi expandido a outras regiões, sendo considerado pelo Ministério da Saúde como a estratégia de reorganização dos serviços básicos de saúde, denominado Estratégia de Saúde da Família (BRASIL, 2002; BRASIL,2006).

A ESF representa a mais importante mudança estrutural já realizada no âmbito da saúde brasileira, firmado pelo Pacto pela Saúde. Este Pacto é um conjunto de reformas institucionais do SUS, pactuado nas três esferas de Governo (União, Estados e Municípios) com o objetivo de promover inovações e instrumentos de gestão, visando alcançar maior eficiência e qualidade das respostas do Sistema Único de Saúde.

Ao mesmo tempo, o Pacto redefine as responsabilidades de cada gestor em função das necessidades de saúde da população e na busca da equidade social. Com a proposta do Pacto, a organização da Atenção Básica tem como principal estratégia a Saúde da Família. Prioriza as ações de promoção, proteção e recuperação da saúde de indivíduos e famílias, de forma integral e contínua, em sintonia com os princípios do SUS (BRASIL, 2006)

A educação dos profissionais é um forte indicador de qualidade, porque representa a estratégia básica de formação dos recursos humanos. Na América Latina, a educação permanente em serviço tem sido divulgada pela Organização Pan-Americana de Saúde - OPAS, desde a década de 80, como um modelo diferenciado de educação de adultos - entendida como um conjunto de processos de aprendizagem que possibilita aos adultos o desenvolvimento de suas capacidades, o enriquecimento de seus conhecimentos e a melhoria de suas competências técnicas ou profissionais (BRASIL, 2005; BRASIL,2007) 
No Brasil, a educação permanente em serviço tem sido adotada como política de desenvolvimento humano para o Sistema Único de Saúde (SUS). Apresenta-se como uma proposta de ação estratégica em cumprimento à Constituição de 1988, à Lei $\mathrm{n}^{\circ}$ 8.080/90 e à Norma Operacional Básica de Recursos Humanos do Sistema Único de Saúde (NOB/RH-SUS), sendo aprovada enquanto política pelas Portarias 198/2004 e 1.996/2007 (BRASIL, 2005; BRASIL2007)

Trata-se de um processo amplo que envolve aspectos do desenvolvimento integral do ser humano, não se limitando a treinamentos formais. Entendida assim, a educação permanente em serviço deixa de ser uma responsabilidade exclusiva dos serviços para ser uma busca, principalmente, da própria pessoa, cuja motivação propicia o uso das experiências vividas no trabalho, na família, na sociedade, para se educar continuamente. Esta educação, além da aquisição de conhecimentos, proporciona a aquisição de uma visão crítica dos problemas vivenciados, responsabilidade social e motivação para continuar a aprender (BRASIL, 2007).

\section{A Educação Permanente em serviço no contexto da Estratégia de Saúde da Família}

Na ESF, a educação permanente constitui-se como um instrumento essencial na capacitação e qualificação dos profissionais, buscando as lacunas de conhecimentos e atitudes que são parte da estrutura explicativa dos problemas identificados no cotidiano dos serviços e dando subsídios para que eles possam entender e atender às necessidades de saúde da população, contribuir na organização dos serviços e na formação dos profissionais da área de saúde (BRASIL, 2007)

No contexto da realização desta pesquisa, as ações educativas da educação permanente consideraram as especificidades regionais, as necessidades de formação dos profissionais e a capacidade de oferta de ações formais de educação na saúde. A gestão ocorria em âmbito regional, por meio de colegiados formados pelos gestores estaduais, municipais, pelas comissões permanentes de integração ensino- serviço, constituídas por gestores, trabalhadores em saúde, instituições de ensino e movimentos sociais. O financiamento obedecia aos critérios de adesão às políticas setoriais de saúde, número de população e profissionais e iniquidades regionais (BRASIL, 2007).

\section{RESULTADOS E DISCUSSÕES.}


As contribuições da educação permanente no cotidiano da Estratégia de Saúde da

Família

Na ESF, a promoção à saúde implica em um novo olhar dos profissionais da equipe multidisciplinar, vislumbrando um conceito ampliado de saúde, tendo a integralidade como princípio de ação, a intersetorialidade, a articulação entre teoria e prática como eixos orientadores. E, neste sentido, para suprir as lacunas de formação destes profissionais para esse novo olhar, o processo de educação permanente em saúde é essencial.

No momento da coleta de dados, este Distrito Sanitário foi cenário de nossa pesquisa, por ficar evidente que o processo de educação permanente em serviço estava presente no cotidiano da ESF, uma vez que neste Distrito desenvolveu-se um projeto de articulação teoria e prática, em que a Universidade, em parceria com as Secretarias Municipal e Estadual de Saúde, ofereceu diversas capacitações com o intuito de qualificar os profissionais, especialmente os que atuavam na ESF, dentre os quais está o enfermeiro.

Os sujeitos do estudo foram 12 enfermeiros que atuavam na Estratégia de Saúde da Família no momento da coleta de dados e realizaram algum curso oferecido pelas secretarias municipal e estadual no processo de educação permanente. Os enfermeiros entrevistados estão na faixa etária entre 20 e 50 anos, a maioria do gênero feminino, entre 5 a 10 anos de experiência e trabalham na ESF desde que saíram de suas graduações.

De acordo com os enfermeiros deste Distrito, o processo de educação permanente traz contribuições para a consolidação da ESF em diversos aspectos e contribuem efetivamente para a qualidade da assistência nesta estratégia.

As falas dos enfermeiros mostram que a educação permanente contribui para a consolidação da ESF, para aprender a trabalhar com a comunidade:

A ESF é uma estratégia comunitária de ações de promoção em saúde, atendimento à comunidade, então o que a gente aprende ajuda a trabalhar na comunidade (E8). Acho que a educação permanente contribui para a ESF, a medida que a gente utiliza o que aprendeu no atendimento ao usuário na forma de cuidar, aprendendo o que é certo ou errado a gente consegue atender melhor as pessoas (E3). 
Fica evidente que o processo de educação permanente em serviço é essencial para o desenvolvimento e consolidação da Estratégia de Saúde da Família, pois existem ainda lacunas na formação dos enfermeiros para esse novo modelo de atenção à saúde e os momentos de capacitação e os conhecimentos adquiridos permitem reflexões sobre a formação, sobre o trabalho, sobre os problemas do serviço, sobre as necessidades de transformações, sobre a necessidade de integrar com a comunidade e esta reflexão permite a elaboração de ações concretas e efetivas no cotidiano de trabalho.

Os profissionais comprometidos com a educação permanente contribuem para a melhor qualidade dos serviços, para a resolutividade, satisfação dos usuários e integração com a comunidade, estimulando nesta a autonomia e o auto-cuidado (BRASIL, 2007)

Para os enfermeiros, o processo de educação permanente em serviço é um processo contínuo que também contribui para a conscientização das necessidades reais de saúde dos usuários e isso possibilita a segurança na realização do trabalho e melhora da qualidade da assistência: A educação permanente é muito importante, visto que, se você está aprendendo constantemente você passa a atender mais consciente e mais seguro e isso melhora a qualidade da assistência (E4).

Os momentos de capacitação têm relevante papel, pois, além do conhecimento técnico-científico, levam os enfermeiros a pensarem sobre como estão trabalhando e como podem melhorar o trabalho

Os enfermeiros relatam que a educação permanente em serviço contribui para atualização de conhecimentos, como forma de crescimento pessoal, de qualificação, que auxilia na prevenção e correção de erros e mudanças de atitudes:

A educação permanente favorece o desenvolvimento pessoal, melhora o processo de trabalho, melhora muito a maneira de agir, melhora a maneira de organizar o serviço porque quando você sabe bem algo isso repercute no seu serviço (E11).

Acho que as capacitações permanentes são importantes para toda a equipe. $O$ agente de saúde, por exemplo, é a porta de entrada da ESF, acho que ele ter conhecimento é fundamental porque o conhecimento dele repercute na comunidade melhorando inclusive indices de morte materna, de gravidez na adolescência, de diabetes e hipertensão (E4).

As capacitações são muito importantes, pois melhoram sua conduta, as ações de educação não permitem que a gente fique ultrapassada, que faça ações que não existem mais, por isso é necessário que as capacitações sejam permanentes (E11). 
A fala dos enfermeiros revela que as capacitações permitem a atualização, favorecem o crescimento pessoal, melhoram o processo de trabalho, uma vez que os conhecimentos assimilados pelos enfermeiros possibilitam o desenvolvimento de aptidões e potencialidades de cada indivíduo e esse desenvolvimento repercute sobre a forma de agir e organizar o trabalho. Como o trabalho na ESF é coletivo e interdisciplinar, o crescimento de cada indivíduo reflete sobre o serviço realizado e sobre a qualidade da assistência como um todo.

A atualização é necessária para a realização do trabalho, visto que o conhecimento é dinâmico e a cada dia surgem novas informações que o profissional precisa buscar e acompanhar. Desta forma, também serve para preencher lacunas do conhecimento, propiciando o crescimento pessoal e profissional, repercutindo na saúde da comunidade (BRASIL, 2007)

De acordo com os enfermeiros, a educação permanente possibilita a transformação da realidade de trabalho, visto que ao se identificar os problemas nas capacitações, buscam-se soluções para a melhoria do trabalho:

Tenho percebido mudanças na prática, no meu dia-a-dia, na forma de realizar meu trabalho, de atender o usuário (E5). Nós não temos números oficiais sobre o impacto das ações educativas na comunidade, mas essas ações influenciam bastante na hora da equipe dialogar em um grupo de educação em saúde, acho que então repercute na comunidade (E2). Acredito que as mudanças no trabalho não dependam das capacitações, mas do profissional que está participando. Toda capacitação trás algum conhecimento vai ser aplicado na prática depende de cada profissional. Acredito que quando a pessoa aplica o que aprendeu na prática pode modificar efetivamente o cotidiano de trabalho (E9).

Os enfermeiros pesquisados referem que desconhecem os indicadores de impacto das ações de educação permanente local, mas reconhecem que a capacitação contribui para as mudanças necessárias ao cotidiano de trabalho. A educação permanente na ESF permite a inserção dos enfermeiros na condição de atores sociais do trabalho, traçando soluções concretas para o seu cotidiano. Assim, esses profissionais são protagonistas da mudança de realidade desejada pelas práticas educativas (BRASIL, 2007)

Entendemos com Freire que a mudança não é um trabalho exclusivo de alguns homens, mas dos homens que a escolhem [...] e estes homens são sujeitos do processo de transformação (FREIRE, 2004). 
As capacitações são necessárias para a formação de profissionais pró-ativos, capazes de fazer reflexões sobre o trabalho e, ainda, com capacidade de diagnosticar e solucionar problemas, de tomar decisões, de intervir no processo, de enfrentar situações em constantes mudanças (BRASIL, 2007).

O processo de formação permanente dos profissionais de saúde tem o intuito de provocar mudanças na prática, garantindo a atenção integral e a qualidade da assistência aos usuários (MANCIA; CABRAL, 2004).

Para os enfermeiros, a educação permanente é capaz de mudar valores e padrões de condutas sobre aspectos da prática profissional: As capacitações contribuem muito para a nossa prática a gente muda valores, padrões, condutas (E6).

A educação se relaciona com os valores; diante de cada situação reage de acordo com a sua escala de valores. Se a situação não vai ao encontro desta escala, o homem tenta transformar essa realidade (PILETTI, 2004).

No processo de educação permanente na ESF, as ações educativas devem ser problematizadas e só serão relevantes se despertarem nos trabalhadores a capacidade de reflexão sobre seus valores e condutas no cotidiano e provocar transformações.

As ações educativas devem levar em consideração o ser humano que está aprendendo e despertar nele a capacidade de pensar sobre o papel do aprendizado, no seu contexto individual e de trabalho, e despertar nele a sua capacidade de ser sujeito do processo de mudança. Portanto, o processo de educação permanente deve levar em consideração os profissionais como protagonistas no campo da prática (BRASIL, 2007).

Para que as capacitações realizadas de forma permanente na ESF tragam efetivas contribuições para essa estratégia, para a conscientização das necessidades reais de saúde da comunidade, para a qualidade da assistência, as ações educativas devem primeiramente despertar o interesse de quem está se capacitando (BRASIL, 2007)

O interesse pelo conhecimento é um fator muito importante para que haja aprendizado. Para que alguém aprenda, é necessário que ele queira aprender. Ninguém consegue ensinar nada a uma pessoa que não quer aprender; por isso a importância da motivação para que aconteça aprendizado (PILETTI, 2004).

Portanto, fica evidente que os profissionais sejam consultados sobre o que querem aprender, de que forma, para que tais ações sejam realmente viáveis, no contexto da ESF. 
Os enfermeiros entrevistados revelam que a equipe da ESF do Distrito onde eles trabalham tem interesse pelas capacitações e isso contribui para que ocorra o processo de aprendizagem: motiva a vontade de aprender que toda equipe. Tenho um grupo de trabalho que é muito bom.

Os aspectos evidenciados nas falas acima mostram que, na ESF, a educação permanente está relacionada ao interesse pessoal pelo aprendizado, à integração, ao trabalho em equipe e à responsabilidade com a comunidade.

A integração da equipe auxilia também no processo de aprendizado. $\mathrm{O}$ trabalho em equipe é uma tendência atual, uma vez que, frente à complexidade e diversidade dos problemas vivenciados na prática, os profissionais devem desenvolver competências associadas à capacidade de cooperação, na resolução de problemas (ASSAD, VIANA, 2005).

\section{CONSIDERAÇÕES FINAIS}

Nesta pesquisa procuramos conhecer a visão dos Enfermeiros sobre a Educação Permanente na ESF quanto as seu significado, vivências e contribuições deste processo para estes profissionais na sua área de atuação.

Ficou evidente que o processo de educação permanente traz contribuições para a consolidação da ESF, estimulando o aperfeiçoamento, a atualização e a qualificação dos trabalhadores para trabalhar com a comunidade. Contribui também para a conscientização das necessidades reais de saúde dos usuários, favorece o crescimento pessoal e profissional, melhora o trabalho em equipe e possibilita mudanças na prática e a melhora na qualidade da assistência.

Para que essas ações educativas no processo de educação permanente tragam contribuições reais para o trabalho na ESF, é necessário levar em consideração o profissional como protagonista do processo e a integração da equipe no processo de ensino-aprendizagem.

\section{REFERÊNCIAS}

ASSAD, L.G.; VIANA, L.O. Formas de aprender na dimensão prática da atuação do enfermeiro assistencial. Revista Brasileira de Enfermagem, v.58, n. 5, 212-232, set. /out. 2005. 
BARDIN, L. Análise de Conteúdo. Lisboa: Edições 70,1977.

BRASIL. Ministério da Saúde. Revista Brasileira de Saúde da Família, Brasília, DF, ano II, n. 5, Edição Especial, 2002.

BRASIL. Ministério da Saúde. Documentos Preparatórios para a $3^{\circ}$ Conferência Nacional de Gestão do Trabalho e da Educação na Saúde. Brasília, DF, 2005.

BRASIL. Ministério da Saúde. Departamento de Atenção Básica. Política Nacional de Atenção Básica. Brasília, DF, 2006

BRASIL. Ministério da Saúde. Portaria GM/MS n.1.996, de 20 de agosto de 2007. Dispõe sobre as diretrizes para a implementação da Política Nacional de Educação Permanente em Saúde e dá outras providências.Diário Oficial da União, n.162, ago.2007.

CECCIM, R. B.; FEUERWERKER, L. O quadrilátero da formação para a área de saúde: ensino, gestão, atenção e controle social. Revista Ciência. Saúde Coletiva, v. 14, n. 2004.

FREIRE. P. Educação e mudança. 28. ed. São Paulo: Paz e Terra, 2005.

GADOTTI, M. Perspectivas atuais da Educação. Porto Alegre: Artes Médicas, 2000

MANCIA, J.R.; CABRAL, L.C; KOERICH, S.M. Educação permanente no contexto da enfermagem e na saúde., v. 57, n. 5,605-610, set./out. 2004.

PILETTI, C. Didática geral. 23. ed. São Paulo: Ática, 2004. 